\title{
Dielectric Properties of Oil Palm Trunk Core
}

\author{
Wun Shun Jie, Hanisom Abdullah, Norjan Yusof, and Zulkifly Abbas
}

\begin{abstract}
Recent development in microwave-assisted processing of biomass materials has significantly created a need for fundamental study to understand the dielectric properties of these biomass feedstock, which could give further insight about interaction between microwave energy and biomass. In the present study, dielectric properties of oil palm trunk (OPT) core were investigated using an open-ended coaxial probe method. The dielectric properties of OPT core were determined as a function of controlling factors such as microwave frequency, biomass moisture content and fibre directions (radial, tangential and cross section). The results showed that dielectric constant of OPT core was decreased with the increasing of frequency. For dielectric loss and loss tangent, a similar trend was observed but only at low frequency $(<1.8 \mathrm{GHz})$. The dielectric constant and loss of OPT core were positively correlated with its moisture content for all fibre directions. In terms of magnitude of dielectric constant and loss, radial direction showed the highest value compared to cross section and tangential which suggests radial direction has the optimum electromagnetic energy absorption and conversion.
\end{abstract}

Index Terms-Oil palm trunk core, dielectric constant, dielectric loss, loss tangent.

\section{INTRODUCTION}

As main exporter of oil palm, Malaysia has a large area of oil palm plantation. Until December 2012, there were 5.08 million ha area of oil palm plantation covering $15 \%$ of the total land area in Malaysia [1]. Oil palm tree has short productivity life span about 25 years. During replanting, it is estimated that around $74 \mathrm{t} / \mathrm{ha}$ dry oil palm trunk (OPT) $\operatorname{logs}$ are produced giving availability of around 13.6 million OPT logs/year for every 100,000 hectares plantations [2]. The abundant OPT logs are mostly utilized in saw-wood, lumber, plywood, flooring and furniture manufacturing [3], [4]. In the manufacturing of plywood, only the outer part of OPT logs was peeled to be further processed into plywood while the core part comprised only soft parenchyma tissue was left out as waste [5]. The core waste could be converted into cattle feed or further processed into biofuel.

For waste conversion of biomass into biofuel and materials, microwave-assisted processes such as microwavepyrolysis and microwave-drying are increasingly applied [2] [6]-[8]. Unlike conventional heat source, microwave energy has several advantageous including volumetric heating allowing bulky and high moisture biomass to be processed, minimize secondary reaction to optimize product yield also permits rapid heating therefore cost and time-saving [6], [8]-

Manuscript received July 9, 2014; revised November 12, 2014.

W. S. Jie, H. Abdullah, N. Yusof are with the Biology Department, Faculty of Science and Mathematics, University Pendidikan Sultan Idris, 35900, Tg. Malim, Perak, Malaysia (e-mail: hanisom@fsmt.upsi.edu.my).

Z. Abbas is with the Physics Department, Faculty of Science, University Putra Malaysia, 43400 Serdang, Selangor, Malaysia.
[11]. The mechanism of microwave energy on biomass involves the transport of the electrical charges by the ions present in the biomass cell wall and cellulose. Once the microwave is encountered the biomass, randomly oriented dipoles in dielectric material align themselves in a direction opposite to applied external electric field. The molecules absorb the energy and store as potential energy. By the mechanism of ionic conduction and dipole rotation, polar molecules vibrate and produce kinetic energy [12].

Dielectric properties can be studied on the energy that is reflected, transmitted through the surface and absorbed by the materials. Each type of energy is specified with its term. Dielectric constant $\left(\varepsilon^{\prime}\right)$ is the ability of material to store electric energy [12]. Dielectric loss ( $\varepsilon$ ") is the ability of material to convert the electromagnetic energy into heat [13]. The relationship of these two values is as equation 1:

$$
\varepsilon^{*}=\varepsilon^{\prime}-j \varepsilon^{\prime \prime}
$$

where $\varepsilon^{*}$ is the complex dielectric constant, while $\varepsilon$ ' and $\varepsilon$ " respectively form the real and imaginary part of $\varepsilon^{*} . j$ is the numerical symbol representing the imaginary part of a complex number [12]. Loss tangent is the ratio of dielectric loss to dielectric constant. It determines the attenuation of microwave power in material which resulted in heating [14]. The dipole rotation is depended on several factors such as moisture, frequency and fibre directions [15].

Previously, dielectric properties of oil palm shell, oil palm fibre [13], empty fruit bunch [14], pine wood [16], rubber wood [17], Blue Gum Wood [18], softwood (Black spruce, Balsam fir and Tamarack) [19], Douglas fir [20], sapwoods (Aspen, White Birch, Yellow Birch and Sugar Maple) [21], sawdust, peanut-hull pellets [22], Australian wood species (Slash pine and Spotted gum) [12], corn, lentil [23], hardwood (Acacia mangium, Swietenia macrophylla and Maescpsis eminii) [15] and switchgrass [11] were reported. However, article about the dielectric properties of OPT is scarce in publicly available literature. Fundamental knowledge about dielectric properties of OPT core are required to understand the interaction between this biomass and microwave energy before subjecting OPT core in microwave-assisted processes. In depth study of OPT core microwave interaction could significantly contribute in optimizing the utilization of this biomass in microwaveassisted process especially in the further study of microwave-assisted carbonization to produce biochar as fuel since it is crucial to know the change of dielectric properties during carbonization [11]. Besides that, knowledge about dielectric properties of OPT core gain from the present study could be further manipulated to determine various important factors such as moisture content of living oil palm biomass in a plantation and detecting defects on wood surfaces as similarly reported previously [20]-[24]. 
This article reports on the effect of frequency, moisture content and fibre directions on the dielectric properties of OPT core. This fundamental knowledge of dielectric properties significantly give further insight in describing the behaviour of OPT core biomass of various moisture content when subjected to various frequency of microwave electric fields.

\section{PROCEDURE}

OPT core logs were obtained from a local plywood factory in Negeri Sembilan, Malaysia. OPT core were the central of an oil palm trunk that make up nearly $80 \%$ of total cross section area of an OPT [25]. The core was formed by scattered vascular bundles that embedded in thin-walled parenchymatous ground tissue [26]. In plywood production, OPT core logs were the waste left after peeling of the outer part of oil palm trunk. In this study, OPT core biomass was cut into cube (dimension $5 \mathrm{~cm} \times 5 \mathrm{~cm} \times 5 \mathrm{~cm}$ ) in three structural directions i.e radial, tangential and cross section (Fig. 1 and Fig. 2) in order to investigate effect of structural direction on dielectric properties. Each OPT cube was polished with sand paper to obtain smooth surface and minimize air bubbles between probe and biomass during conducting measurement because presence of air gap might cause error in measuring by using open-ended coaxial probe. For preparing OPT core biomass with different moisture, the biomass was ovendried at $60 \pm 2^{\circ} \mathrm{C}$ at different time intervals following method described in a previous study [14].

Dielectric properties of OPT were measured using openended coaxial probe which was attached to an automatic network analyser (model HP 85070-D) as illustrated in Fig 3. It is a non-destructive measuring method as it would not cause any changes on biomass characteristics during measurement. The 3.5 diameter open-ended probe was placed on the biomass according the fibre direction during measurement. This measurement method was based on the input reflection coefficient of coaxial line against the samples [14]. Dielectric properties were measured from the phase and amplitude of the reflected signal at the end of an open-ended coaxial line inserted into a sample to be measured [27].

Range of frequency was set from $1 \mathrm{GHz}$ to $3 \mathrm{GHz}$ as openended coaxial probe method could be used for wide range of frequencies $(0.5 \mathrm{GHz}$ to $110 \mathrm{GHz})$. It is valid for frequency
$0.915 \mathrm{GHz}$ and $2.45 \mathrm{GHz}$ and materials with loss factors greater than 1 [27]. After calibration with distilled water, probe sensor was placed on the OPT biomass to start the dielectric measurement. The measurement of dielectric properties for each testing was repeated multiple times to increase the data accuracy and validity. From the measurement, dielectric constant and loss were obtained while loss tangent was calculated from dielectric constant and loss. The averaged value was reported in this article. Two way ANOVA test (SPSS Version 21) was conducted on the mean values to evaluate the significance difference of all parameters assessed in this study.

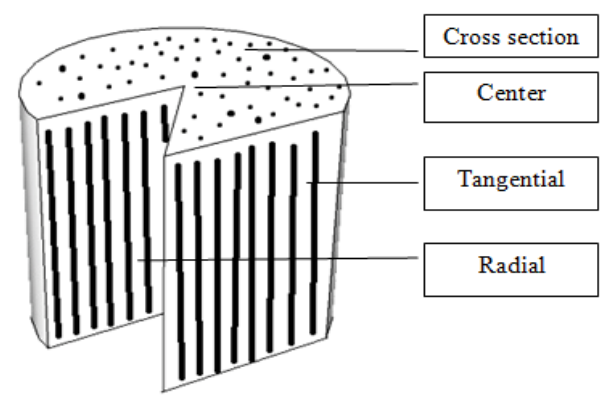

Fig. 1. Structural direction of OPT

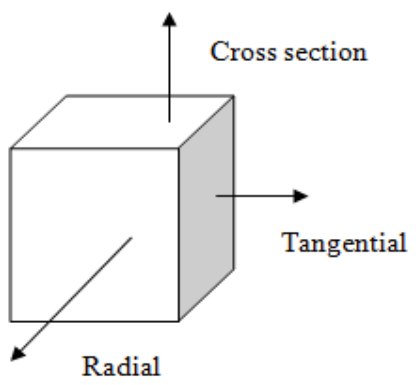

Fig. 2. Structural direction on OPT cube.

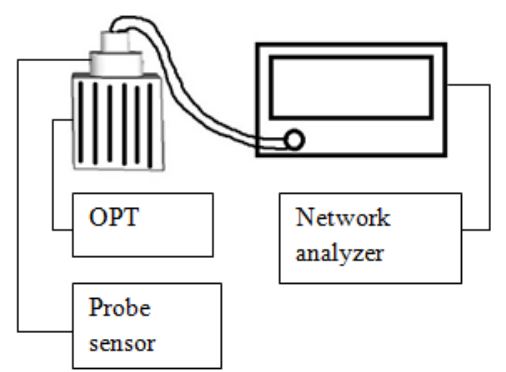

Fig. 3. Measurement of dielectric properties set up rig.

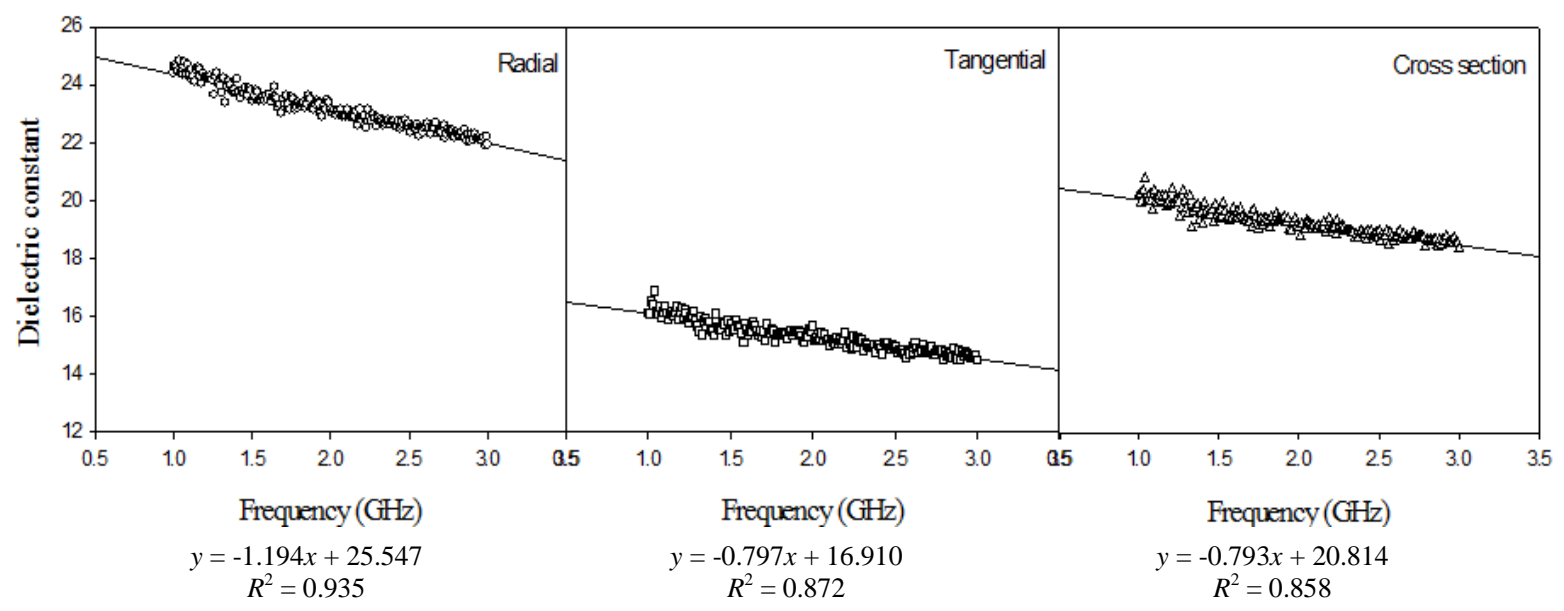

Fig. 4. Dielectric constant, $\varepsilon$ ' as a function of frequency for all fibre directions of oil palm trunk. 


\section{RESULTS AND DISCUSSION}

\section{A. Effect of Frequency}

Experiment was performed at frequency $1 \mathrm{GHz}$ to $3 \mathrm{GHz}$ for investigate the effect of frequency on dielectric properties of OPT and the results are shown in Fig. 4-Fig. 6. Fig. 4 shows the relationship between dielectric constant and frequency for all of the fibre directions. When frequency was increased from 1 to $3 \mathrm{GHz}$, dielectric constant was decreased for all of the fibre directions. The result depicted that electric field of microwave affected the interaction of OPT core biomass with electromagnetic waves. When the frequency increased, a continuous varying electric field was created. This varying electric field created polarization in OPT core. Dipole moment in biomass gradually decreased as frequency increased. Therefore, dipole had shorter time to realign itself according the oscillating electric field [13], [28]. Conductive effect of microwave heating also diminished quickly in high frequency [14]. Hence, dielectric constant which indicated the ability of material to store electric energy decreased.

$\mathrm{R}$ squared for each of the fibre directions was more than 0.8 where regression lines quite strong fit with the actual data of dielectric constant. The trend of decreasing dielectric constant with the increasing of frequency was found to be similar with other biomass tested previously such as rubber wood [17], softwood included Black spruce, Balsam fir and Tamarak [19], empty fruit bunch of oil palm [14], oil palm shell, oil palm fibre, biochar from oil palm shell [13], green pea flour, lentil flour and soybean flour [29].

In Fig. 4, all of the fibre directions show a similar trend. In comparing different fibre directions, radial direction significantly showed the highest dielectric constant magnitude compared to cross section and tangential direction. Standard error of the replication of this experiment was small $(<0.50)$. The significant value for dielectric constant data under factors frequency and fibre directions was less than 0.05 which showed the factors were highly significant and both factors are strong correlated with dielectric constant. Hence, it is suggested that radial direction of OPT core has the optimum ability of storing electric energy than tangential and cross section. Differences in the intrinsic structural arrangement of cells in each of the fibre direction may cause the differences in their dielectric constant.

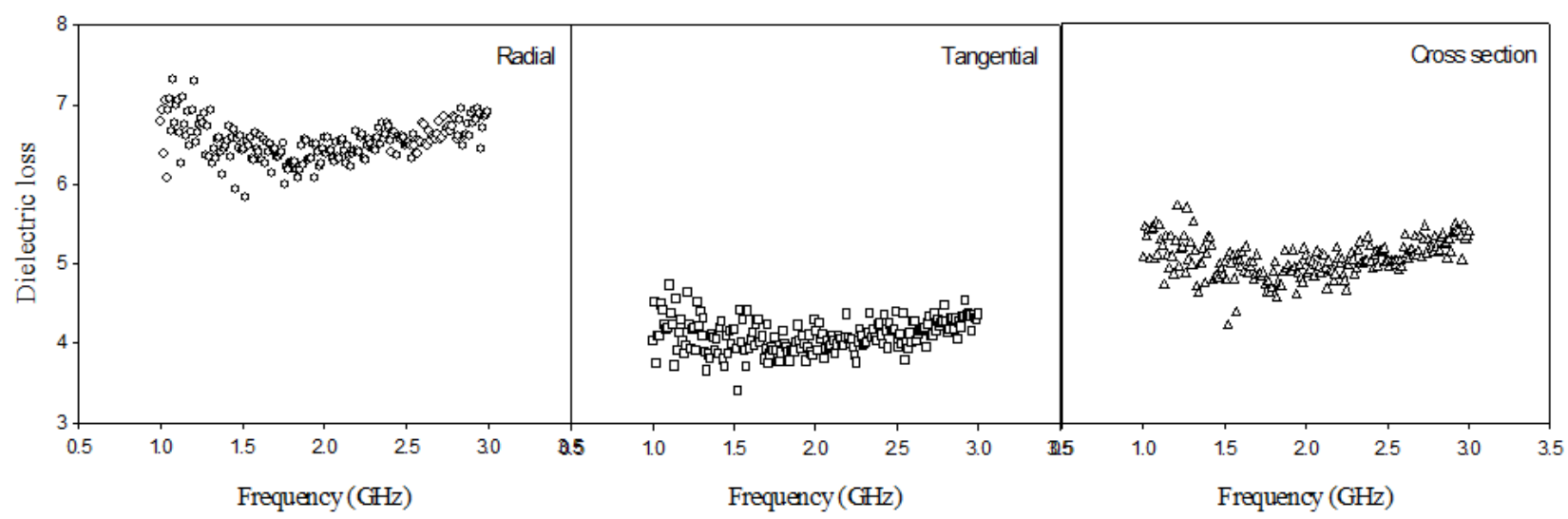

Fig. 5. Dielectric loss, $\varepsilon$ " as a function of frequency for all fibre directions of oil palm trunk.

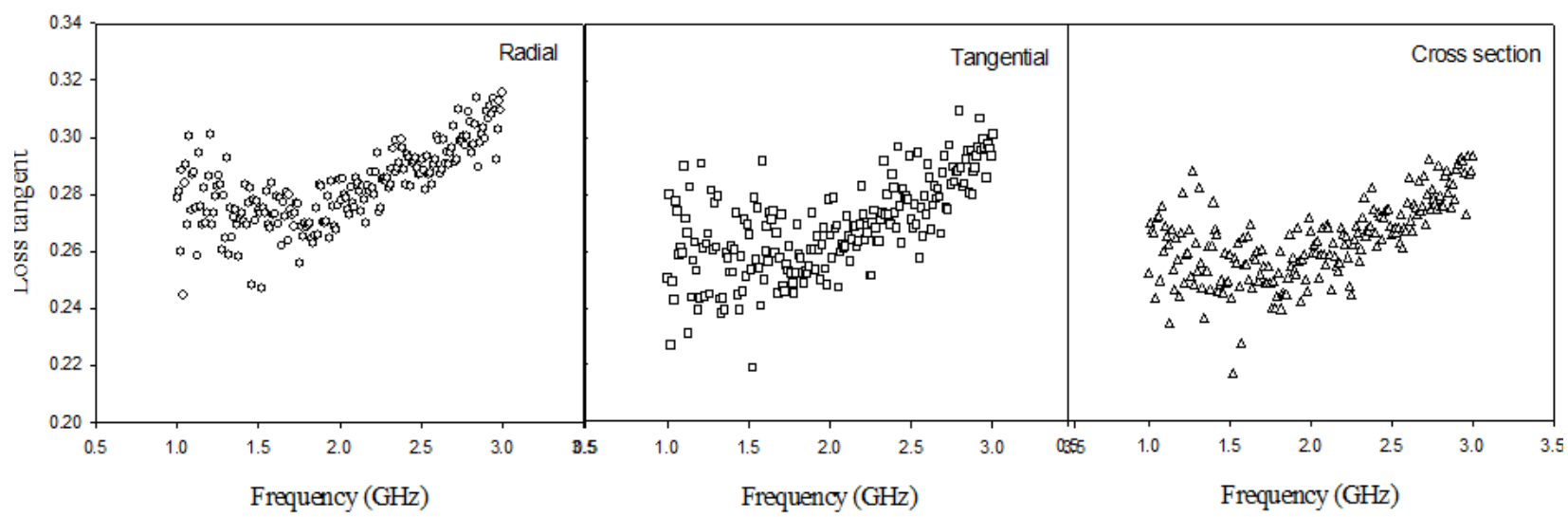

Fig. 6. Loss tangent, $\tan \delta$ as a function of frequency for all fibre directions of oil palm trunk.

In Fig. 5, dielectric loss of all fibre directions was decreased when the frequency increased from $1 \mathrm{GHz}$ to $1.8 \mathrm{GHz}$. Beyond $1.8 \mathrm{GHz}$, the dielectric loss was slightly increased with the increasing of frequency. This dielectric loss trend was observed due to electrical conductivity of certain oil palm biomass was different at varying frequency as reported in an earlier study [13]. Amongst various OPT core fibre directions (Fig. 5), the radial direction again gave the highest dielectric loss value compared to cross section and tangential direction. The results in Fig. 4 and Fig. 5 highlighted that radial direction can be further optimized to conduct microwave related reaction since more absorbed energy can be converted into heat.

There was strong correlation between dielectric loss and frequency with significant value less than 0.05 . Significant value for fibre direction was also less than 0.05. Standard error on the replication of this experiment was less than 0.30 . Hence, dielectric loss can be affected by both frequency and 
fibre direction.

Loss tangent, $\tan \delta=\varepsilon " / \varepsilon '$ describes the overall efficiency of OPT core to convert microwave radiation into heat [30]. In Fig. 6, the relationship between loss tangent and frequency is not linear. Loss tangent of all fibre directions (Fig. 6) shows a similar trend as their dielectric loss due to largely depend on their dielectric loss factors.

\section{B. Effect of Moisture Content}

Effect of moisture content on dielectric properties was studied at frequency $2.45 \mathrm{GHz}$. Initially, the moisture content of OPT core as received was about $65 \%$. It was expected that the moisture content largely affects dielectric properties. The free moisture in biomass contributes in the interaction between biomass and electromagnetic fields [12]. In the present study, dielectric constant of the three fibre directions were positively correlated with OPT core moisture content as showed in Fig. 7. However, the regression analysis of dielectric constant for tangential direction produced lower $\mathrm{R}$ squared value $\left(R^{2}=0.580\right)$.

In general, water is well known as good microwave energy absorber due to its dielectric property and nature [7], [13], and [14]. The result in the present study highlights the moisture develops high polarization in OPT core once the microwave encounter OPT core. More microwave energy was absorbed in OPT core of increasing moisture content. Dielectric constant as the parameter used to describe the ability of molecules to be polarized by electric field increased with the increasing of moisture content OPT core. Fig. 7 showed dielectric constant was low for low moisture content OPT core because effect of rotation water dipoles diminished when the moisture content was low. These correlation trends are similar with other biomass reported previously such as empty fruit bunch [14], softwood [19], pine wood [16], corn, lentil [23], hard red winter wheat and yellow dent field corn [31].

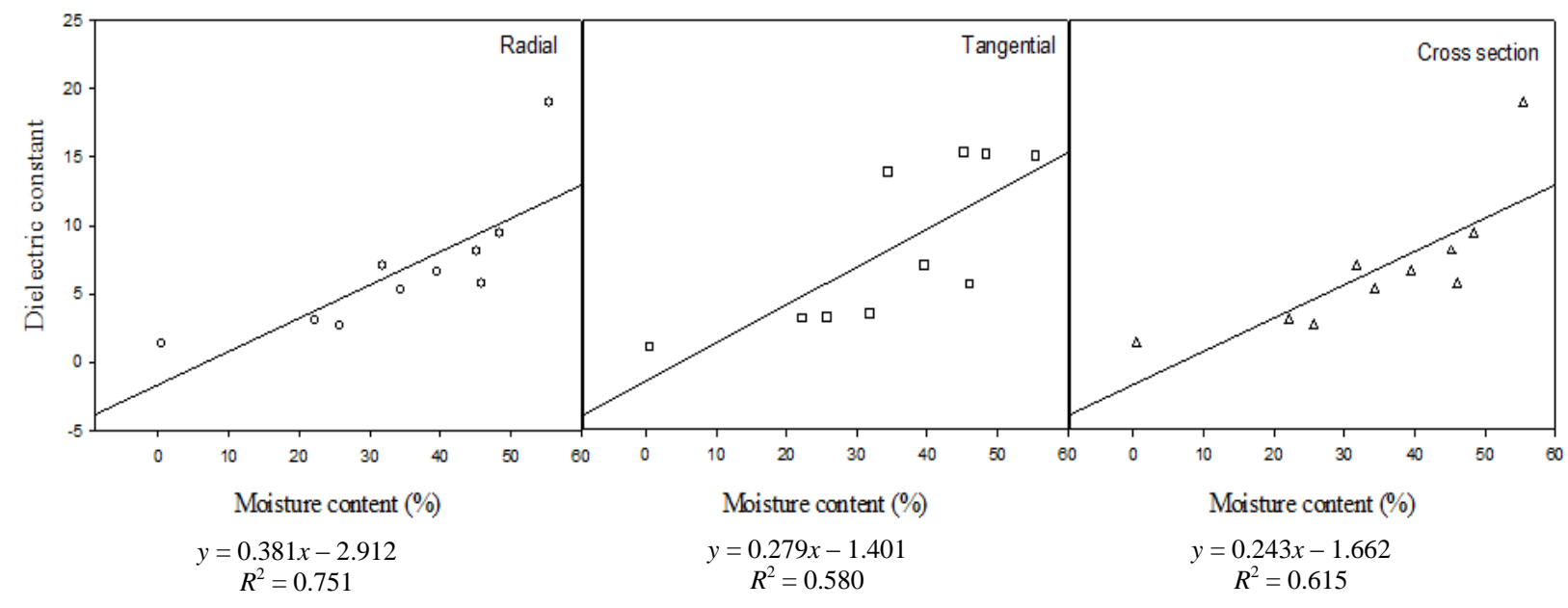

Fig. 7. Dielectric constant, $\varepsilon$ ' as a function of moisture content for all fibre directions of oil palm trunk.

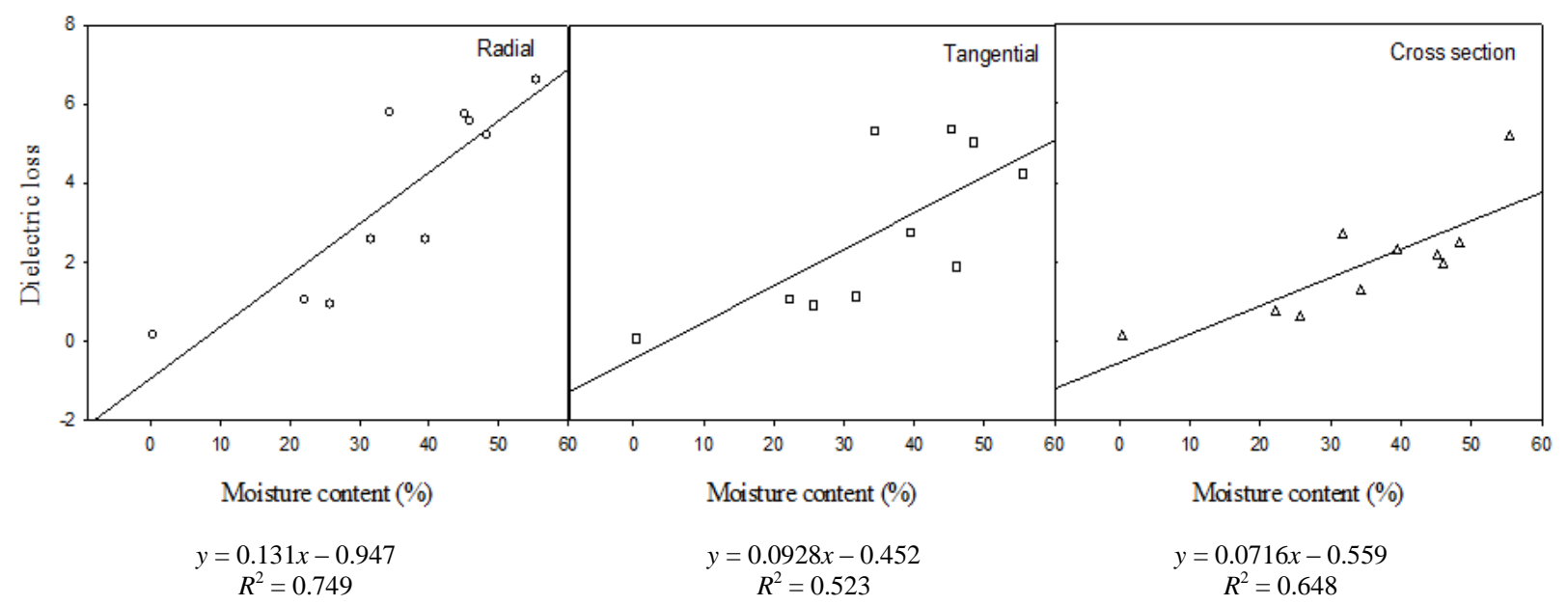

Fig. 8. Dielectric loss, $\varepsilon$ " as a function of moisture content for all fibre directions of oil palm trunk.

For radial direction, dielectric loss increased rapidly as the moisture content increased (Fig. 8). The slope of linear plot of dielectric loss for radial direction was steeper than tangential and cross section. This observation showed dielectric loss increased with the increasing of moisture content regardless the fibre directions. Water absorbed the microwaves and created dielectric polarization. Water molecules tend to realign itself in the electric field and create friction within the molecules. Heat energy was generated through the friction within the molecules.

Analysis of two ways ANOVA helped to study the relationship between dielectric loss, moisture content and fibre directions. Dielectric loss was found to depend on moisture content and fibre directions with significant value less than 0.05 (standard error on the replication of the experiment was less than 0.15 ). 
Both dielectric constant and dielectric loss increased with the rise in moisture content OPT but the rate of increasing dielectric loss (Fig. 8) was lesser than the dielectric constant (Fig. 7). As loss tangent depends on both dielectric constant and loss therefore, loss tangent of radial and tangential increased with the increasing of moisture content until around $45 \%$. At high moisture $(>45 \%)$, the loss tangent value started to decrease. This showed th e overall efficiency of OPT to convert microwave radiation into heat increased at low moisture but decreased at high moisture content.

Loss tangent of a material can be classified into three levels which showed in Table I [30], [16].

From Fig. 6 and Fig. 9, loss tangent of OPT core for all fibre directions were obtained in the range of 0.1 to 0.3 with both frequency and moisture content parameters. Hence, OPT core can be classified as medium microwave absorbing biomass according to Table I which is also similar to many oil palm biomasses. Biomass with higher loss tangent will be more advantage in rapid heating because the rate of convention of electromagnetic energy into heat was higher [30].

TABLE I: CLASSIFICATION OF LOSS TANGENT [16], [30]

\begin{tabular}{ccl}
\hline \hline Level & $\begin{array}{c}\text { Loss tangent } \\
(\tan \delta)\end{array}$ & \multicolumn{1}{c}{ Material } \\
\hline Low & $<0.1$ & $\begin{array}{l}\text { Pinus sylvestris (L.) wood with 8 wt. \% } \\
\text { moisture content at tangential, radial and } \\
\text { transverse direction }\end{array}$ \\
Medium & $0.1-0.5$ & $\begin{array}{l}\text { Dried EFB (oil palm empty fruit bunch) } \\
\text { char, EFB sample with 18 wt.\% moisture, } \\
\text { EFB sample with 64 wt.\% moisture } \\
\text { Coconut activated carbon, EFB sample } \\
\text { with 45 wt.\% moisture }\end{array}$ \\
\hline \hline
\end{tabular}

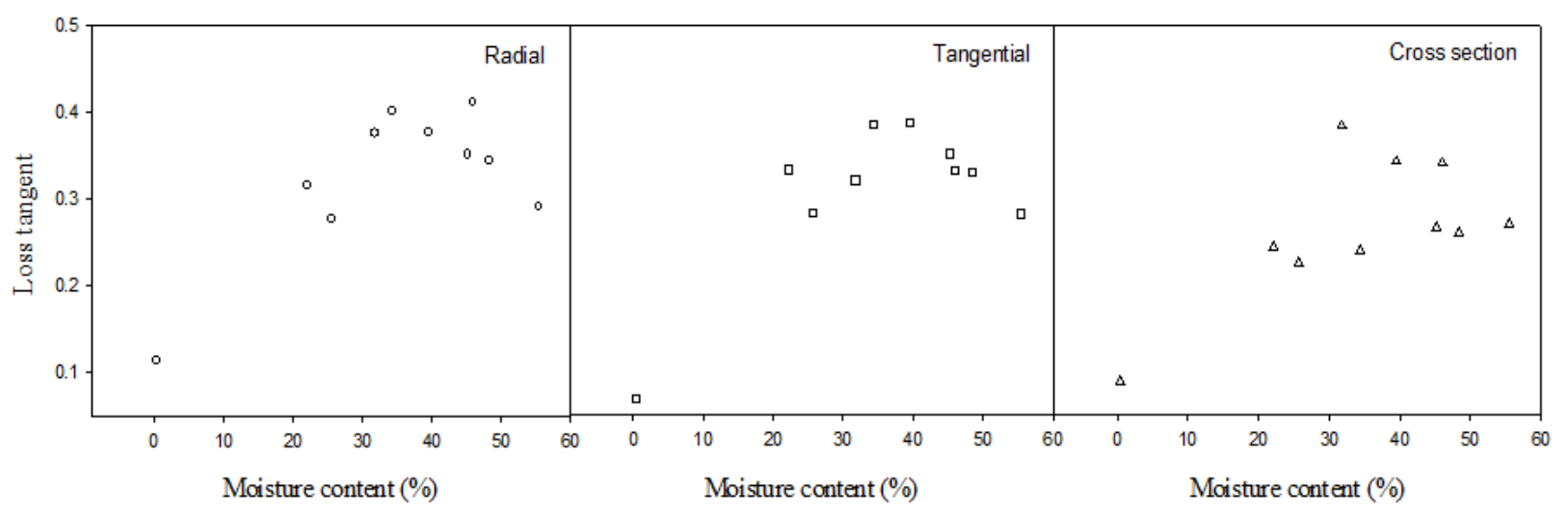

Fig. 9. Loss tangent, $\tan \delta$ as a function of moisture content for all fibre directions of oil palm trunk.

\section{CONCLUSION}

In this study, it can be concluded that, dielectric constant of OPT core decreased with the increasing of frequency while the increasing of frequency did not show significant effect to dielectric loss. Dielectric constant and loss of OPT core was found to correspond positively with moisture content. OPT core can be classified as a medium microwave absorbing biomass.

\section{ACKNOWLEDGMENT}

The authors are grateful to Kementerian Tenaga, Teknologi Hijau dan Air and Kementerian Pengajian Tinggi for funding the FRGS Grant Code 2012-0001-104-02. We also thank Plus Intervest Sendirian Berhad for supplying oil palm biomass for this research, staffs at Physic Department, Faculty of Science, Universiti Putra Malaysia for technical assistance in dielectric measurement.

\section{REFERENCES}

[1] A. H. R. Aljuboori, "Oil palm biomass residue in Malaysia: Availability and sustainability," Int. J. Biomass Renewables, vol. 2. pp. 13-18, 2013.

[2] P. Amouzgar, H. P. S. A. Khalil, B. Salamatinia, A. Z. Abdullah, and M. Issam, "Optimization of bioresource material from oil palm trunk core drying using microwave radiation; a response surface methodology application," Bioresour. Technol., vol. 101, no. 21, pp. 8396-8401, Nov. 2010

[3] I. W. Asma, S. Mahanim, H. Zulkafli, S. Otman, and Y. Mori, "Malaysian oil palm biomass," 2010.
[4] N. Abdullah and F. Sulaiman, "The oil palm wastes in Malaysia," Biomass Now-Sustainable Growth and Use, pp. 75-100, 2013.

[5] Y. Loh, P. Tahir, and B. Yeoh, "Density distribution of oil palm stem veneer and its influence on plywood mechanical properties," J. Appl. Sci., vol. 11, no. 5, pp. 824-831, 2011.

[6] J. P. Robinson, S. W. Kingman, R. Barranco, and C. E. Snape, "Microwave pyrolysis of wood pellets," Ind. Eng. Chem. Res., vol. 49, no. 2, pp. 459-463, 2010.

[7] A. A. Salema and F. N. Ani, "Bioresource technology microwave induced pyrolysis of oil palm biomass," Bioresour. Technol., vol. 102, no. 3, pp. 3388-3395, 2011.

[8] J. A. Menéndez, M. Inguanzo, and J. J. Pis, "Microwave-induced pyrolysis of sewage sludge," Water Res., vol. 36, no. 13, pp. 32613264, Jul. 2002.

[9] J. A. Menéndez, A. Domínguez, M. Inguanzo, and J. J. Pis, "Microwave-induced drying, pyrolysis and gasification (MWDPG) of sewage sludge: Vitrification of the solid residue," J. Anal. Appl. Pyrolysis, vol. 74, no. 1-2, pp. 406-412, Aug. 2005.

[10] J. A. Menéndez, A. Arenillas, B. Fidalgo, Y. Fernández, L. Zubizarreta, E. G. Calvo, and J. M. Bermúdez, "Microwave heating processes involving carbon materials," Fuel Process. Technol., vol. 91, no. 1, pp. 1-8, 2010.

[11] F. Motasemi, M. T. Afzal, A. A. Salema, J. Mouris, and R. M. Hutcheon, "Microwave dielectric characterization of switchgrass for bioenergy and biofuel," Fuel, vol. 124, pp. 151-157, 2014.

[12] S. Ramasamy and B. Moghtaderi, "Dielectric properties of typical Australian wood-based biomass materials at microwave frequency," Energy Fuels, vol. 24, no. 12, pp. 4534-4548, 2010.

[13] A. A. Salema, Y. K. Yeow, K. Ishaque, F. N. Ani, M. T. Afzal, and A. Hassan, "Dielectric properties and microwave heating of oil palm biomass and biochar," Ind. Crop. Prod., vol. 50, pp. 366-374, 2013.

[14] R. Omar, A. Idris, R. Yunus, K. Khalid, and M. I. A. Isma, "Characterization of empty fruit bunch for microwave-assisted pyrolysis," Fuel, vol. 90, no. 4, pp. 1536-1544, 2011.

[15] I. Husein, S. Sadiyo, N. Nugroho, I. Wahyudi, A. Agustina, R. N. Komariah, J. Khabibi, C. Y. C. P. D. Ali, M. Iftor, T. P. Kahar, A Wijayanto, and M. Jamilah, "Electrical properties of Indonesian 
hardwood case study: Acacia Mangium, Swietenia Macrophylla and Maesopsis Eminii," Wood Res., vol. 59, no. 4, pp. 695-704, 2014.

[16] H. S. Kol, "Thermal and dielectric properties of pine wood in the transverse direction," BioResources, vol. 4, no. 4, pp. 1663-1669, 2009.

[17] M. F. Kabir, W. M. Daud, K. B. Khalid, and H. A. A. Sidek, "Temperature dependence of the dielectric properties of rubber wood," Wood Fiber Sci., vol. 33, no. 2, pp. 233-238, 2001.

[18] G. Daian, A. Taube, A. Birnboim, M. Daian, and Y. Shramkov, "Modeling the dielectric properties of wood," Wood Sci. Technol., vol. 40, pp. 237-246, 2006.

[19] M. T. Afzal, B. Colpitts, and K. Galik, "Dielectric properties of softwood species measured with an open-ended coaxial probe," in Proc. 8th International IUFRO Wood Drying Conference, 2003, pp. $110-115$.

[20] J. B. Forrer and J. W. Funck, "Dielectric properties of defects on wood surfaces," Holz als Roh- und Werkst., vol. 56, no. 1, pp. 25-29, Jan. 1998.

[21] A. Koubaa, P. Perré, R. Hutcheon, and J. Lessard, "Complex dielectric properties of the sapwoods of Aspen, White Birch, Yellow Birch and Sugar Maple," Dry. Technol., vol. 26, no. 5, pp. 1-46, 2008

[22] A. M. Paz, "The dielectric properties of solid biofuels," Malardalen University Sweden, 2010.

[23] M. Soltani and R. Alimardani, "Prediction of corn and lentil moisture content using dielectric properties," J. Agric. Technol., vol. 7, no. 5, pp. 1223-1232, 2011.

[24] C. L. Jones, M. L. Stone, N. O. Maness, J. B. Solie, and G. H. Brusewitz, "Plant biomass estimation using dielectric properties," in Proc. American Society of Agricultural and Biological Engineers Annual International Meeting, 2006, vol. 0300.

[25] O. Sulaiman, N. Salim, N. A. Nordin, R. Hashim, M. Ibrahim, and M. Sato, "The potential of oil palm trunk biomass as an alternative source for compressed wood," BioResources, vol. 7, no. 2, pp. 2688-2706, 2012.

[26] R. Dungani, M. Jawaid, H. P. S. A. Khalil, Jasni, S. Aprilia, K. R. Hakeem, S. Hartati, and M. N. Islam, "A review on quality enhancement of oil palm trunk waste by resin impregnation: future materials," BioResources, vol. 8, no. 2, pp. 3136-3156, 2013.

[27] M. Venkatesh and G. S. V. Raghavan, "An overview of dielectric properties measuring techniques," Can. Biosyst. Eng., vol. 47, no. 7, pp. 15-30, 2005.

[28] Z. Ahmad, "Polymeric dielectric materials," Dielectric Material, pp. 3-26, 2012.

[29] W. Guo, S. Wang, G. Tiwari, J. A. Johnson, and J. Tang, "Temperature and moisture dependent dielectric properties of legume flour associated with dielectric heating," LWT-Food Sci. Technol., vol 43, no. 2, pp. 193-201, 2010.

[30] C. Yin, "Microwave-assisted pyrolysis of biomass for liquid biofuels production.," Bioresour. Technol., vol. 120, pp. 273-84, Sep. 2012.
[31] S. O. Nelson and S. Trabelsi, "Factors influencing the dielectric properties of agricultural and food products," J. Mircowave Power Electromagn. Energy, vol. 46, no. 2, pp. 93-107, 2012.

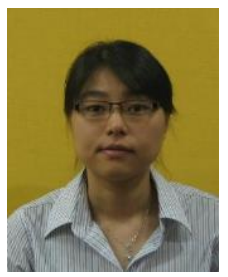

Wun Shun Jie is currently a postgraduate student in Biology Program at Sultan Idris University of Education. Her research interest focuses on the use of oil palm biomass as biofuel.

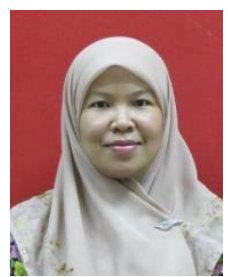

Hanisom Abdullah obtained her B.Sc. degree in biomedical science from the Faculty of Health Alliance Science, National University of Malaysia, and her M.Sc. degree in chemistry from the Faculty of Science University of Technology Malaysia and $\mathrm{PhD}$ degree in chemical engineering, from Curtin University. She is currently a senior lecturer at the Biology Department, Faculty of Science and Mathematics, University Pendidikan Sultan Idris, Malaysia. Her research interest focuses on the use of biomass as energy, biocomposites and sorption materials.

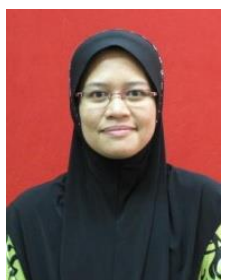

Norjan Yusof had obtained her BSc. degree in science biotechnology from University Putra Malaysia, MSc degree in environmental management from University Putra Malaysia and $\mathrm{PhD}$ degree in engineering bioprocess from Kyushu Institute of Technology. She is currently a senior lecturer at the Biology Department, Faculty of Science and Mathematics, University Pendidikan Sultan Idris. Her to value added products. research interest focuses on organic waste conversion

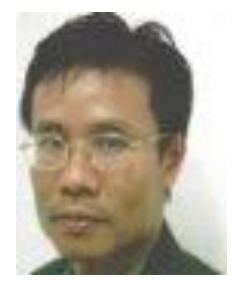

Zulkifly Abbas obtained his B.Sc. degree from the University of Malaya, M.Sc. degree in microwave instrumentation from the University Putra Malaysia and the Ph.D. degree in electronic and electrical engineering from the University of Leeds, Leeds, U.K. He is currently an associate professor at Physics Department, University Putra Malaysia. His research interest focuses on microwave sensors, electromagnetic wave propagation theory and microwave instrumentation. 